ISSN 0103-9954

\title{
EFEITO DO TEMPO E DA TEMPERATURA DE MODIFICAÇÃO TÉRMICA NA REDUÇÃO DO INCHAMENTO MÁXIMO DA MADEIRA DE Eucalyptus grandis Hill ex Maiden
}

\author{
EFFECT OF TIME AND TEMPERATURE OF THERMAL MODIFICATION ON THE REDUCTION \\ OF MAXIMUM SWELLING OF Eucalyptus grandis Hill ex Maiden WOOD
}

Djeison Cesar Batista $^{1}$ Ivan Tomaselli² Ricardo Jorge Klitzke ${ }^{3}$

\begin{abstract}
RESUMO
A modificação térmica de madeiras é uma técnica que foi desenvolvida na década de 40 do século XX e tem sido largamente estudada e aplicada industrialmente na Europa. No Brasil a pesquisa neste tema ainda é pequena e pulverizada, porém vem ganhando destaque atualmente. O objetivo deste trabalho foi avaliar a influência do tempo e da temperatura de modificação térmica na redução do inchamento máximo da madeira de Eucalyptus grandis. De acordo com os resultados obtidos podem-se obter reduções do inchamento volumétrico máximo da madeira de Eucalyptus grandis superiores a 50\%. Melhores resultados foram obtidos com a modificação térmica a temperatura de $230^{\circ} \mathrm{C}$ do que a $200^{\circ} \mathrm{C}$. O fator temperatura foi mais significativo do que o fator tempo, uma vez que não houve diferença significativa entre os diferentes tempos utilizados (1, 2 e 3 horas). Não houve interação significativa entre estes fatores na modificação térmica.
\end{abstract}

Palavras-chave: modificação térmica; madeira; Eucalyptus grandis.

\begin{abstract}
Thermal modification of wood was developed in the decade of 1940 and has been largerly studied and produced in Europe. In Brazil, the research about this technique is still little and sparse, but it has gained attention nowadays. The aim of this study was to evaluate the influence of time and temperature of modification on the reduction of maximum swelling of Eucalyptus grandis wood. According to the results obtained it is possible to achieve reductions of about $50 \%$ on the maximum volumetric swelling of Eucalyptus grandis wood. The best results were obtained for $230^{\circ} \mathrm{C}$ of thermal modification rather than $200{ }^{\circ} \mathrm{C}$. The factor temperature was more significant than time, once that there was no significant difference between the times used (1,2 and 3 hours). There was no significant interaction between the factors time and temperature.
\end{abstract}

Keywords: thermal modification; wood; Eucalyptus grandis.

\section{INTRODUÇÃO}

A anisotropia, palavra que tem origem em um prefixo (an= não, negação) e dois radicais gregos (iso=igual; tropos=direção), pode ser interpretada como "direção desigual". O material madeira possui esta propriedade física, que nesse caso particular é definida como uma movimentação desigual das diferentes direções estruturais da madeira. Esta característica torna a madeira um material peculiar, diferenciando-a dos metais e plásticos.

Kollmann e Côté Júnior (1968) afirmam que a tendência da madeira de contrair e inchar com as trocas de umidade é a propriedade mais desfavorável deste material. Assim, melhorar a estabilidade dimensional da madeira é uma procura constante em todos os segmentos que utilizam madeira maciça como matéria-prima.

1. Engenheiro Florestal, Mestre, Professor Assistente do Departamento de Engenharia Florestal, Centro de Ciências Agrárias, Universidade Federal do Espírito Santo, Av. Governador Carlos Lindemberg, 316, CEP 29550-000, Jerônimo Monteiro (ES). djeison1984@gmail.com

2. Engenheiro Florestal, Ph.D., Professor Titular do Departamento de Engenharia e Tecnologia Florestal, Universidade Federal do Paraná, Campus III, CIFLOMA, Jardim Botânico, Av. Lothario Meissner, 900, CEP 80210-170, Curitiba (PR). itomaselli@stcp.com.br

3. Engenheiro Florestal, Dr., Professor Adjunto do Departamento de Engenharia e Tecnologia Florestal, Universidade Federal do Paraná, Campus III, CIFLOMA, Jardim Botânico, Av. Lothario Meissner, 900, CEP 80210-170, Curitiba (PR).rklitzke@ufpr.br

Recebido para publicação em 20/05/2009 e aceito em 3/09/2010 
Uma das técnicas utilizadas para reduzir a higroscopicidade da madeira é a estabilização por aquecimento. Esta prática está em destaque atualmente, e tem sido tema abordado por alguns pesquisadores brasileiros (PINCELLI et al., 2002, BORGES e QUIRINO, 2004; BRITO et al., 2006). No entanto, Borges e Quirino (2004) relatam que o tratamento térmico com a finalidade de conferir estabilidade dimensional à madeira já era estudado na década de 40 do século XX, com o nome comercial de staybwood (madeira estável).

De acordo com Shi et al. (2007), o tratamento térmico da madeira a altas temperaturas, com vistas à redução da higroscopicidade, tem sido estudado há anos na Europa. Poncsák et al. (2006), citando Militz (2002), afirmam que existem muitas tecnologias desenvolvidas na Europa, sendo as mais conhecidas: PLATO Process (Holanda), Retification Process (França), Bois Perdure Process (França), OHT Process (Alemanha) e Thermo Wood Process (Finlândia).

A madeira modificada termicamente obtida pelo princípio da termodegradação de seus constituintes na ausência de oxigênio, ou forte deficiência de ar. É definida, também, como o produto de uma pirólise controlada, interrompida antes de atingir o patamar das reações exotérmicas (que se iniciam aproximadamente à temperatura de $280^{\circ} \mathrm{C}$ ), quando se inicia a combustão espontânea (BORGES e QUIRINO, 2004). O resultado é a obtenção de um produto sólido que apresenta características diferenciadas, comparativamente à madeira que o originou, algumas delas interessantes para aplicações diferenciadas da madeira (BRITO et al., 2006).

De um modo geral, todos os processos desenvolvidos na Europa atuam na modificação da estrutura química da madeira a temperaturas que variam de $160^{\circ} \mathrm{C}$ a $260^{\circ} \mathrm{C}$, em um processo com três etapas: aquecimento, secagem (redução do teor de umidade a aproximadamente $0 \%$ ) e por último, resfriamento e acondicionamento (SHI et al., 2007).

Após o tratamento a temperaturas superiores a $180^{\circ} \mathrm{C}$ ocorrem mudanças químicas na lignina e na hemicelulose, e a madeira tratada torna-se menos higroscópica (SHI et al., 2007). Durante o tratamento térmico, o número de grupos hidroxílicos $\left(\mathrm{OH}^{-}\right)$é reduzido e substituído por grupos hidrofóbicos $O$-acetil. Estes últimos criam ligações cruzadas entre as fibras reduzindo significantemente a possibilidade da água de penetrar na madeira (PONCSÁK et al., 2006).
As hemiceluloses degradam-se primeiro (entre $160^{\circ} \mathrm{C}$ e $260^{\circ} \mathrm{C}$ ) devido ao baixo peso molecular e estrutura ramificada, que facilitam a degradação quando comparada à celulose e lignina (FENGEL e WEGENER, 1984).

De acordo com Stamm (1964) esta degradação das hemiceluloses gera furfural (tipo de açúcar) e outros polímeros provenientes da quebra de açúcares, que são menos higroscópicos que as hemiceluloses que os formou.

Desta maneira, a madeira modificada termicamente torna-se mais estável dimensionalmente, quando comparada à madeira não tratada, pela redução dos grupamentos hidroxílicos, que são os pontos de adsorção das moléculas de água (SKAAR, 1972).

Assim, o sucesso da modificação térmica da madeira, bem como a sua eficiência, depende de uma série de fatores, entre os quais, temperatura máxima, taxa de aquecimento, tempo de duração na temperatura máxima, umidade do ambiente circundante (PONCSÁK et al., 2006); ambiente circundante (atmosfera redutora ou oxidante), tempo de tratamento total, espécie (Borges e Quirino, 2004); natureza e pressão da fase gasosa, geometria e tamanho das amostras e teor de umidade inicial (PINCELLI et al., 2002).

Borges e Quirino (2004) afirmam que a modificação térmica é pouco pesquisada no Brasil, apesar de seus benefícios comprovados em espécies europeias, onde este tratamento já foi bastante abordado.

Como observado, são diversos os fatores que influenciam na modificação térmica da madeira. Esta dificuldade explica, em parte, o desinteresse científico nacional, onde a diversidade de espécies ainda facilita a escolha de determinada madeira (mais adequada) a uma aplicação desejada. Porém, a pressão ambiental e o forte apelo pela não utilização das espécies nativas já são do conhecimento do senso comum da sociedade brasileira e, portanto, é crescente a opinião social contra a utilização destas espécies.

Neste cenário encontram-se os plantios comerciais de Eucalyptus, que ocupam, de acordo com dados da Associação Brasileira dos Produtores de Florestas Plantadas (ABRAF), cerca de 4,7 milhões de hectares implantados (ABRAF, 2011). A madeira de Eucalyptus é conhecida tecnologicamente pela sua elevada instabilidade dimensional, sendo vetada e discriminada em aplicações que exijam esta propriedade. A 
modificação térmica da madeira de Eucalyptus (aliada a outras técnicas de prática corrente) pode tornar-se uma realidade para a indústria nacional, no sentido de melhorar a estabilidade dimensional. Para tal, mais estudos quanto à aplicação desta técnica devem ser realizados, sempre visando à aplicação prática em escala industrial.

O objetivo deste trabalho foi avaliar a influência do tempo e da temperatura de modificação térmica na redução do inchamento máximo da madeira de Eucalyptus grandis.

\section{MATERIAL E MÉTODOS}

\section{Caracterização do material e amostragem}

Foram utilizadas tábuas tangenciais de Eucalyptus grandis de $30 \mathrm{~mm}$ de espessura, 150 $\mathrm{mm}$ de largura e $740 \mathrm{~mm}$ de comprimento, isentas de defeitos, secas em câmara convencional até a umidade final de $10 \%$. De cada tábua foram confeccionados cinco corpos de prova devidamente orientados e livres de defeitos. Na Figura 1 encontra-se o esquema de amostragem dos corpos de prova, exemplificando-se as duas primeiras tábuas utilizadas. As tábuas seguintes obedeceram à sequência lógica de amostragem.

Como se pode observar, cada tratamento foi composto por corpos de prova representativos de toda a seção longitudinal de diferentes tábuas. A amostragem foi realizada desta maneira visando minimizar o efeito da heterogeneidade da madeira, e assim, distribuir homogeneamente fontes de erro que pudessem ser superiores ao efeito dos tratamentos.

\section{Tratamentos}

Na Tabela 1 encontram-se os tratamentos. $\mathrm{O}$ tratamento testemunha não sofreu modificação térmica, sendo realizado o ensaio de inchamento com algumas modificações.

\section{Avaliação da redução do inchamento máximo}

Para estudar o efeito dos tratamentos de modificação térmica na redução do inchamento máximo da madeira utilizaram-se 12 corpos de prova de $25 \times 25 \times 100 \mathrm{~mm}$ de comprimento por tratamento, de acordo com o ensaio de inchamento da norma COPANT 462 (1972).

Inicialmente todos os corpos de prova foram submetidos a aquecimento de acordo com o programa a seguir: $60^{\circ} \mathrm{C}$ por $2 \mathrm{~h} ; 80^{\circ} \mathrm{C}$ por $2 \mathrm{~h} \mathrm{e}$ $120^{\circ} \mathrm{C}$ por $20 \mathrm{~h}$. O objetivo do aquecimento foi assegurar que todos os corpos de prova tivessem as mesmas condições de umidade inicial $(0 \%)$. Tanto

TABELA 1: Diferentes condições de tempo e temperatura utilizadas nos tratamentos.

TABLE 1: Different times and temperatures used in the treatments.

\begin{tabular}{ccc}
\hline Tratamento & Tempo (horas) & Temperatura $\left({ }^{\circ} \mathrm{C}\right)$ \\
\hline Testemunha & - & - \\
\hline 1 & 1 & 200 \\
\hline 2 & 2 & \\
\hline 3 & 3 & \\
\hline 4 & 1 & 230 \\
\hline 5 & 2 & \\
\hline 6 & 3 & \\
\hline
\end{tabular}

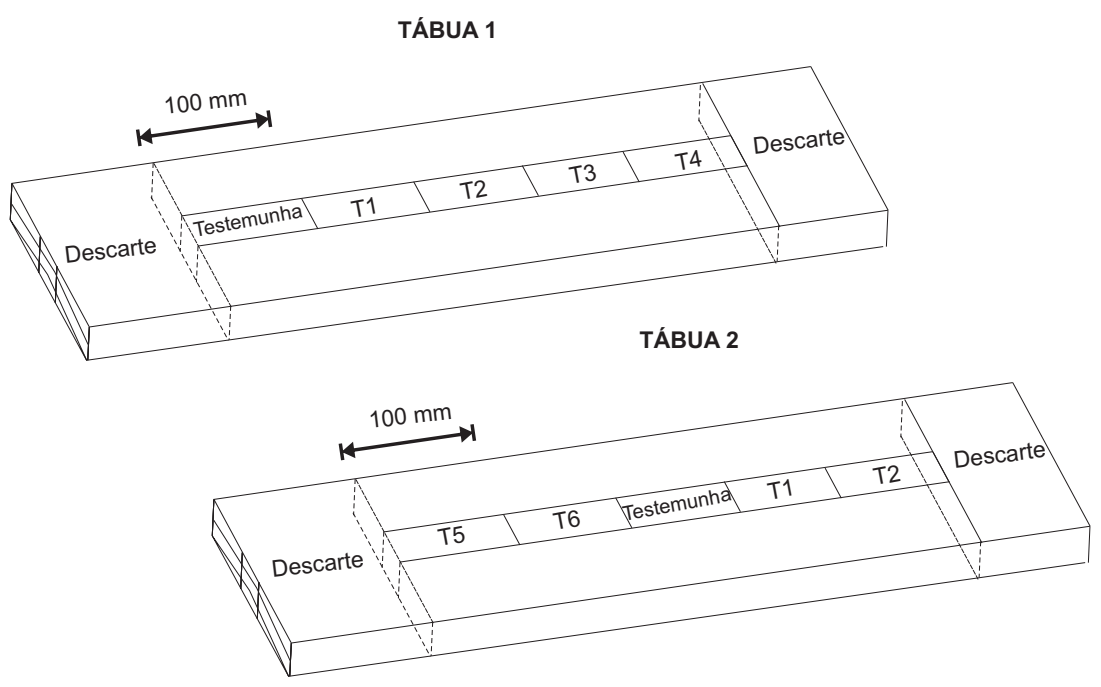

FIGURA 1: Esquema de amostragem dos corpos de prova.

FIGURE 1: Specimen sampling scheme. 
o aquecimento quanto a modificação térmica foram conduzidos em uma estufa com controlador digital de precisão de $\pm 2{ }^{\circ} \mathrm{C}$.

\section{Tratamento testemunha}

Depois da fase de aquecimento, os corpos de prova do tratamento testemunha foram pesados em balança digital $(0,01 \mathrm{~g}$ de precisão) e medidos com micrômetro digital $(0,001 \mathrm{~mm}$ de precisão) nas diferentes direções estruturais, determinandose as suas dimensões na condição anidra. Em seguida, os corpos de prova foram imersos em água até obterem massa constante, pesados e medidos pela última vez, simulando a condição saturada.

\section{Modificação térmica}

As temperaturas de modificação térmica foram escolhidas com base no trabalho de Brito et al. (2006), em que estes autores obtiveram redução significativa da retratibilidade a partir da temperatura de $200^{\circ} \mathrm{C}$; e os tempos utilizados foram escolhidos com base no trabalho de Shi et al. (2007).

Decorrida a fase de aquecimento inicial, os corpos de prova dos tratamentos de modificação térmica foram pesados em balança digital $(0,01$ $\mathrm{g}$ de precisão) e medidos com micrômetro digital (0,001 mm de precisão) nas diferentes direções estruturais, determinando-se as suas dimensões na condição anidra. Em seguida procedeu-se a modificação térmica, a qual inicialmente, a estufa foi pré-aquecida na temperatura desejada, e em seguida os corpos de prova foram mantidos pelo tempo estabelecido de acordo com cada tratamento.

Terminada a modificação térmica, os corpos de prova foram resfriados em dessecador, pesados e medidos a semelhança do tratamento testemunha, para a determinação das dimensões na condição de modificação térmica. $\mathrm{O}$ restante do ensaio de inchamento ocorreu da mesma maneira que o tratamento testemunha.

\section{Equações}

\section{Ensaio de inchamento máximo}

O inchamento máximo foi calculado de acordo com a Equação 1. Para os tratamentos que foram modificados termicamente a dimensão seca correspondeu àquela após a modificação térmica.

$$
\alpha=\frac{(D V-D S)}{D S} \times 100
$$

Em que:

$\alpha$ : inchamento máximo (\%);

DV: dimensão saturada (mm);

DS: dimensão seca (mm). A redução do inchamento máximo foi

calculada de acordo com a Equação 2.

$$
R \alpha=100-\left(\frac{\alpha_{r t}}{\alpha_{\text {testemunha }}} \times 100\right)
$$

Em que:

$\mathrm{R} \alpha$ : redução do inchamento em uma dada direção estrutural (\%);

$\alpha_{\mathrm{rt}}$ : inchamento máximo de um tratamento modificado termicamente em uma dada direção estrutural (\%);

$\alpha_{\text {testemunha }}$ : inchamento máximo do tratamento testemunha em uma dada direção estrutural (\%).

\section{Densidade básica}

Com os mesmos corpos de prova do ensaio de inchamento determinou-se a densidade básica dos tratamentos de acordo com a Equação 3.

$$
D B=\frac{M S}{V V}
$$

Em que:

DB: densidade básica $\left(\mathrm{g} / \mathrm{cm}^{3}\right)$;

MS: massa na condição seca (testemunha) ou modificada termicamente $(\mathrm{g})$;

VV: volume após saturação em água $\left(\mathrm{cm}^{3}\right)$.

\section{Redução de massa}

A redução de massa decorrente do tratamento de modificação térmica foi calculada de acordo com a Equação 4 (PONCSÁK et al., 2006).

$$
R=\frac{(M 1-M 2)}{M 1} \times 100
$$

Em que:

$\mathrm{R}$ : redução de massa (\%);

M1: massa seca antes da modificação térmica $(\mathrm{g})$;

M2: massa seca depois da modificação térmica (g).

\section{Análise estatística}

Inicialmente aplicou-se o teste t de "Student" ( $5 \%$ de significância) para a comparação das médias de densidade básica de cada tratamento modificado termicamente contra o tratamento testemunha.

Em seguida, aplicou-se a análise de 
variância (ANOVA) em arranjo fatorial $(5 \%$ de significância) entre as duas temperaturas $\left(200^{\circ} \mathrm{C}\right.$ e $230^{\circ} \mathrm{C}$ ) e os três tempos $(1 \mathrm{~h}, 2 \mathrm{~h}$ e $3 \mathrm{~h}$ ), resultando em seis tratamentos, cada um com 12 repetições, aos resultados dos tratamentos modificados termicamente para verificar a existência de interação entre os fatores temperatura e tempo. Havendo rejeição da hipótese da nulidade, aplicou-se o teste de Tukey ( $5 \%$ de significância) para diferenciação das médias.

\section{RESULTADOS E DISCUSSÕES}

\section{Densidade}

A densidade básica média do tratamento testemunha foi de $0,44 \mathrm{~g} / \mathrm{cm}^{3}$, inferior ao resultado obtido por Rocha (2000), de $0,47 \mathrm{~g} / \mathrm{cm}^{3}$ para a madeira de Eucalyptus grandis com 12 anos de idade. Pereira et al. (2000) obtiveram médias de densidade básica de $0,48 \mathrm{~g} / \mathrm{cm}^{3}, 0,49 \mathrm{~g} / \mathrm{cm}^{3}$ e 0,51 $\mathrm{g} / \mathrm{cm}^{3}$, respectivamente para as idades de 10,9 e 8 anos em árvores desta mesma espécie.

$\mathrm{Na}$ Tabela 2 encontram-se as médias de densidade básica dos tratamentos e os resultados do teste $t$ de "Student" aplicado entre as médias dos tratamentos modificados termicamente e o tratamento testemunha.

De acordo com o teste $t$ de "Student" a densidade básica dos tratamentos modificados termicamente $\mathrm{a} 200^{\circ} \mathrm{C}$ não diferiu estatisticamente do tratamento testemunha, enquanto a dos tratamentos modificados a $230^{\circ} \mathrm{C}$ diferiu estatisticamente. Brito et al. (2006) também observaram aumento proporcional da densidade básica com a temperatura de modificação térmica até a temperatura de $200^{\circ} \mathrm{C}$, porém ressaltaram que esse aumento não havia sido significativo, fato idêntico ao ocorrido neste trabalho. É conhecido que o aumento da temperatura promove a concomitante perda de massa, porém, Brito et al. (2006) sugeriram que o aumento da temperatura não foi suficiente para provocar uma perda de massa da mesma proporção da redução do volume.

Como a madeira utilizada foi inicialmente seca a $0 \%$ de umidade, soma-se ao efeito da modificação térmica o efeito da histerese na redução da higroscopicidade da madeira. A histerese pode ter contribuído para a redução do inchamento e, por conseguinte, reduzido o volume saturado da madeira.

Apesar de toda a discussão e suposições sobre o aumento não significativo da densidade básica para os tratamentos modificados a $200^{\circ} \mathrm{C}$, para a temperatura de $230^{\circ} \mathrm{C}$ o aumento da densidade básica foi significativo, contrariando a bibliografia especializada sobre este tema (FINNISH THERMOWOOD ASSOCIATION, 2003). Assim, os autores optaram por outra forma de análise da densidade, comparando-se a densidade anidra do tratamento testemunha com a densidade após a modificação térmica dos corpos de prova modificados, de acordo com a Tabela 2.

De acordo com o teste $\mathrm{t}$ de "Student" não houve diferença significativa entre a densidade anidra do tratamento testemunha e a densidade depois da modificação térmica dos tratamentos modificados a $200^{\circ} \mathrm{C}$, significando que a perda de massa (Tabela 3) não foi suficiente para reduzir a densidade a esta temperatura. Porém, para os tratamentos modificados a $230^{\circ} \mathrm{C}$ houve diferença significativa, a qual a densidade dos corpos de prova foi inferior ao tratamento testemunha, mostrando que nesse caso a perda de massa foi significativa na redução da densidade.

Tanto para a densidade básica quanto para a densidade anidra aplicou-se a ANOVA em ensaio fatorial e os resultados revelaram que não houve interação significativa entre os fatores tempo e temperatura ( $\mathrm{Fc}$ densidade básica $=0,23^{\text {ns }}$ e Fc densidade anidra $\left.=0,10^{\text {ns }}\right)$ sobre os tratamentos

TABELA 2: Teste t de "Student" para a densidade básica.

TABLE 2: Test $\mathrm{t}$ of Student for basic density.

\begin{tabular}{ccccccc}
\hline Tratamento & Densidade Básica $\left(\mathrm{g} / \mathrm{cm}^{3}\right)$ & $\mathrm{CV}(\%)$ & Valor de t & Densidade anidra $\left(\mathrm{g} / \mathrm{cm}^{3}\right)$ & $\mathrm{CV}(\%)$ & Valor de t \\
\hline Testemunha & 0,44 & 12,3 & - & 0,56 & 19,6 & - \\
1 & 0,47 & 16,7 & $1,19^{\text {ns }}$ & 0,53 & 18,9 & $0,59^{\text {ns }}$ \\
2 & 0,48 & 13,9 & $1,78^{\text {ns }}$ & 0,55 & 12,7 & $0,32^{\text {ns }}$ \\
3 & 0,46 & 18,9 & $0,63^{\text {ns }}$ & 0,52 & 21,1 & $0,91^{\text {ns }}$ \\
4 & 0,52 & 16,6 & $2,65^{*}$ & 0,46 & 6,5 & $2,72 *$ \\
5 & 0,50 & 14,0 & $2,39^{*}$ & 0,46 & 6,5 & $2,86^{*}$ \\
6 & 0,50 & 14,8 & $2,25^{*}$ & 0,44 & 2,3 & $3,51^{* *}$ \\
\hline
\end{tabular}

Em que: $\mathrm{CV}=$ coeficiente de variação; ${ }^{\text {ns }}=$ não significante; $*=$ significante a $5 \%, * *=$ significante a $1 \%$. 
modificados termicamente. Então, analisaramse os fatores separadamente, e a ANOVA revelou que apenas o fator temperatura foi significante (Fc densidade básica $=16,20 * *$ e Fc densidade anidra $=$ $\left.18,34^{* *}\right)$, o que já havia sido evidenciado de acordo com o teste $t$ de "Student".

\section{Redução de massa}

$\mathrm{Na}$ tabela 3 encontram-se as médias de redução de massa dos tratamentos modificados termicamente, em relação à massa do tratamento testemunha.

$O$ resultado da ANOVA em ensaio fatorial revelou não haver interação significativa entre os fatores tempo e temperatura $\left(\mathrm{F}\right.$ calculado $=0,47^{\mathrm{ns}}$ ) sobre a redução de massa da madeira dos tratamentos modificados termicamente. Analisaram-se os fatores separadamente, e a ANOVA revelou que apenas o fator temperatura foi significante ( $\mathrm{F}$ calculado $=$ $80,32 * *)$ na redução de massa. O teste de Tukey (5\%) confirmou essa tendência, o qual as médias dos tratamentos a $200^{\circ} \mathrm{C}$ não diferiram estatisticamente entre si e da mesma forma ocorreu entre os tratamentos a $230^{\circ} \mathrm{C}$.

Brito et al. (2006) obtiveram médias de redução de massa de $5,19 \%$ e $9,68 \%$ para madeira

TABELA 3: Médias de redução de massa.

TABLE 3: Averages of weight loss.

\begin{tabular}{ccc}
\hline Tratamentos & Redução de massa $(\%)$ & CV $(\%)$ \\
\hline 1 & $5,04 \mathrm{a}$ & 9,4 \\
2 & $5,48 \mathrm{a}$ & 12,8 \\
3 & $5,33 \mathrm{a}$ & 8,8 \\
4 & $8,13 \mathrm{~b}$ & 9,8 \\
5 & $8,72 \mathrm{~b}$ & 11,4 \\
6 & $8,01 \mathrm{~b}$ & 9,9 \\
\hline
\end{tabular}

Médias seguidas de uma mesma letra em uma mesma coluna não diferem entre si de acordo com o teste de Tukey a 5\% de significância.

TABELA 4: Médias de inchamento máximo.

TABLE 4: Averages of maximum swelling.

\begin{tabular}{ccccccc}
\hline \multirow{2}{*}{ Tratamentos } & \multicolumn{7}{c}{ Inchamento máximo (\%) } \\
\cline { 2 - 7 } & Radial & CV & Tangencial & CV & Volumétrico & CV \\
\hline Testemunha & $6,16 \mathrm{~d}$ & 21,64 & $9,50 \mathrm{c}$ & 11,03 & $16,47 \mathrm{c}$ & 13,72 \\
1 & $4,65 \mathrm{bc}$ & 27,28 & $7,93 \mathrm{~b}$ & 18,18 & $13,28 \mathrm{~b}$ & 20,76 \\
2 & $4,96 \mathrm{~cd}$ & 11,72 & $7,64 \mathrm{~b}$ & 11,42 & $13,25 \mathrm{~b}$ & 8,38 \\
3 & $4,83 \mathrm{~cd}$ & 31,26 & $7,35 \mathrm{~b}$ & 24,28 & $12,85 \mathrm{~b}$ & 27,35 \\
4 & $3,35 \mathrm{ab}$ & 20,60 & $5,23 \mathrm{a}$ & 17,12 & $8,94 \mathrm{a}$ & 18,30 \\
5 & $3,06 \mathrm{a}$ & 22,78 & $4,88 \mathrm{a}$ & 19,17 & $8,27 \mathrm{a}$ & 20,69 \\
6 & $3,05 \mathrm{a}$ & 21,55 & $4,82 \mathrm{a}$ & 17,16 & $8,14 \mathrm{a}$ & 18,94 \\
\hline
\end{tabular}

Médias seguidas de uma mesma letra em uma mesma coluna não diferem entre si de acordo com o teste de Tukey a $5 \%$ de significância. de Eucalyptus grandis modificada a $180^{\circ} \mathrm{C}$ e $200^{\circ} \mathrm{C}$, respectivamente. Neste trabalho, a madeira de Eucalyptus grandis perdeu menos massa em relação às médias obtidas por Brito et al. (2006), com médias de $5,28 \%$ e $8,29 \%$ para os tratamentos a $200^{\circ} \mathrm{C}$ e $230^{\circ} \mathrm{C}$, respectivamente. Esperava-se maior redução de massa no tratamento a $230^{\circ} \mathrm{C}$, uma vez que a esta temperatura ocorre maior degradação de lignina e, principalmente, hemiceluloses, do que à temperatura de $200^{\circ} \mathrm{C}$ (Pinheiro et al., 2008).

\section{Ensaio de inchamento máximo}

$\mathrm{Na}$ Tabela 4 encontram-se as médias de inchamento máximo por tratamento.

$\mathrm{O}$ tratamento testemunha apresentou as maiores médias de inchamento total, enquanto o tratamento 6 apresentou as menores médias. As médias absolutas de inchamento, de maneira geral, diminuíram com o aumento da temperatura e do tempo de modificação térmica. Somente a média de inchamento radial máximo do tratamento 1 não obedeceu este padrão.

Em seguida, analisou-se a interação dos fatores tempo e temperatura sobre as médias dos tratamentos modificados termicamente. Na Tabela 5 encontram-se os valores de $\mathrm{F}$ calculado na ANOVA em fatorial.

De acordo com a Tabela 5, a influência do fator tempo isoladamente não foi significativa na redução do inchamento máximo. Da mesma maneira, não houve interação entre os fatores tempo e temperatura. Somente o fator temperatura foi significativo a $1 \%$, exercendo influência na redução do inchamento máximo radial, tangencial e volumétrico.

Esse resultado também pode ser observado na Tabela 4, principalmente na diferenciação das médias de inchamento máximo tangencial e volumétrico. As médias dos tratamentos se

Ci. F1., v. 21, n. 3, jul.-set., 2011 
TABELA 5: Valores de F calculado - tabela da ANOVA.

TABLE 5: F calculated values - ANAVA table.

\begin{tabular}{ccc}
\hline Inchamento máximo & Fator & F calculado \\
\hline \multirow{2}{*}{ Radial } & Temperatura & $45,52^{* *}$ \\
\cline { 2 - 3 } & Tempo & $0,03^{\text {ns }}$ \\
\cline { 2 - 3 } & Temperatura x Tempo & $0,58^{\text {ns }}$ \\
\cline { 2 - 3 } Tangencial & Temperatura & $79,57^{* *}$ \\
\cline { 2 - 3 } & Tempo & $0,96^{\text {ns }}$ \\
\cline { 2 - 3 } Volumétrico & Temperatura x Tempo & $0,05^{\text {ns }}$ \\
\cline { 2 - 3 } & Temperatura & $70,13^{* *}$ \\
\cline { 2 - 3 } & Tempo & $0,41^{\text {ns }}$ \\
\cline { 2 - 3 } & Temperatura x Tempo & $0,11^{\text {ns }}$ \\
\hline
\end{tabular}

Em que: ${ }^{\text {ns }}=$ não significativo a $5 \% ; * *=$ significativo a $1 \%$.

distinguiram por temperatura, nos quais as médias dos tratamentos modificados termicamente a $230^{\circ} \mathrm{C}$ (4,5 e 6) não diferiram estatisticamente entre e si e foram menores que as dos demais tratamentos.

Os resultados de inchamento máximo obtidos estão em desacordo com o proposto por Vital e Della Lucia (1982), que afirmaram que o efeito da temperatura nas variações dimensionais depende do tempo de modificação térmica. Estes autores estudaram cinco tempos diferentes $(10,20,40,80$ e 160 horas), superiores aos deste e estudo, porém, com temperaturas inferiores $\left(105,130\right.$ e $\left.155^{\circ} \mathrm{C}\right)$. Portanto, o efeito do tempo de modificação térmica parece ser significativo apenas a temperaturas mais baixas, perdendo a sua importância à medida que temperaturas superiores são utilizadas.

Como os diferentes tempos utilizados (1, 2 e 3 horas) não foram estatisticamente significantes, recomenda-se apenas 1 hora de tratamento, por representar menor consumo de energia e redução de custos.

\section{Redução do inchamento máximo}

Na Figura 2 encontra-se o gráfico de redução do inchamento máximo por tratamento modificado termicamente.

$\mathrm{Na}$ Figura 2 observa-se claramente a influência do fator temperatura sobre a modificação térmica, como discutido ao longo do trabalho. Para os tratamentos a $200^{\circ} \mathrm{C}$ a redução do inchamento volumétrico máximo foi da ordem de $20 \%$ em relação ao tratamento testemunha, enquanto para os tratamentos modificados a $230^{\circ} \mathrm{C}$ a redução foi de 45 a $50 \%$ em relação ao tratamento testemunha. A redução do inchamento máximo obedeceu ao padrão de perda de massa na modificação térmica (Tabela 3), no qual a maior perda de massa resultou em maior redução no inchamento.

Esses resultados estão de acordo com aqueles relatados na literatura (STAMM, 1964;

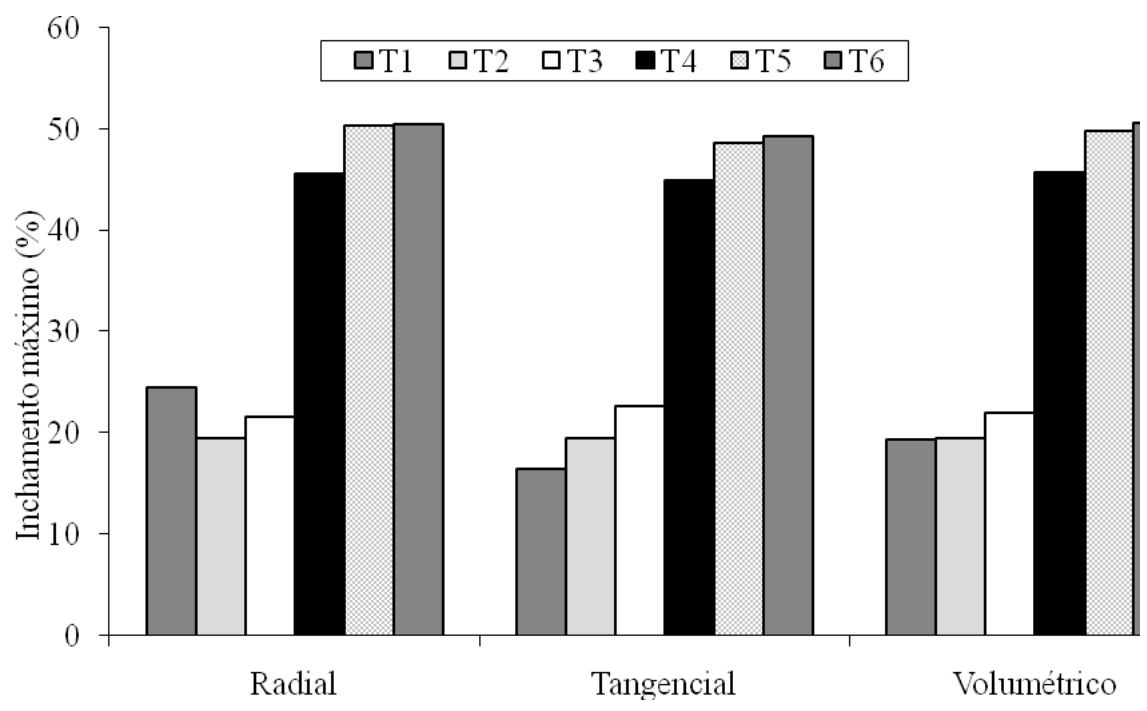

FIGURA 2: Redução do inchamento máximo.

FIGURE 2: Reduction of maximum swelling. 
FENGEL e WEGENER, 1984), os quais afirmam que a degradação dos constituintes da madeira, principalmente as hemiceluloses, torna a madeira menos higroscópica, resultando em concomitante redução na anisotropia de contração e inchamento, este último, de interesse para o presente estudo. As temperaturas utilizadas neste trabalho foram suficientes para causarem o início da degradação da lignina, uma degradação mais severa das hemiceluloses e um provável início de degradação da celulose (PINHEIRO et al., 2008), porém, como não foi objetivo deste estudo, não quantificou-se a perda de massa destes constituintes causada pela modificação térmica e a real influência de cada um deles na redução do inchamento máximo.

\section{CONCLUSÕES}

De acordo com os resultados obtidos, conclui-se para a madeira de Eucalyptus grandis modificada termicamente:

- A modificação térmica foi eficaz na redução do inchamento máximo;

- Dentre os fatores estudados, a temperatura foi mais relevante que o tempo;

- Os tempos de modificação térmica utilizados neste trabalho, de 1, 2 e 3 horas, não foram estatisticamente significativos para a redução do inchamento máximo;

- A temperatura de modificação térmica de $230^{\circ} \mathrm{C}$ foi mais eficiente que a temperatura de $200^{\circ} \mathrm{C}$ na redução do inchamento máximo;

- A modificação térmica alterou a coloração da madeira, tornando-a mais escura.

\section{REFERÊNCIAS BIBLIOGRÁFICAS}

ASSOCIAÇÃO BRASILEIRA DOS

PRODUTORES DE FLIORESTAS PLANTADAS (ABRAF). Anuário Estatístico da ABRAF 2011 ano base 2010. ABRAF: Brasília, 2011. $130 \mathrm{p}$. BORGES, L. M.; QUIRINO, W. F. Higroscopicidade da madeira de Pinus caribaea var hondurensis tratado termicamente. Biomassa \& Energia, Viçosa, v. 1, n. 2, p. 173-182, abr./jun. 2004.

BRITO, J. O. et al. Densidade Básica e Retratibilidade da Madeira de Eucalyptus grandis, submetida a diferentes temperaturas de termorretificação. Cerne, Lavras, v. 12, n. 2, p. 182-188, abr.jun. 2006.

CINIGLIO, G. Avaliação da secagem de madeira serrada de E. grandis e E. urophylla. Piracicaba, 1998. 69 f. Dissertação (Mestrado em Engenharia
Florestal)-Escola superior de Agricultura Luiz de Queiroz, Universidade de São Paulo, Piracicaba, 1998.

COPANT (COMISSÃO PANAMERICANA DE NORMAS TÉCNICAS). Método de determinación de la contracción - Norma panamericana COPANT 462, 1972.

FENGEL, D.; WEGENER, G. Wood, chemistry, ultraestructure, reactions. Berlin: Walter de Gruiter \& Co., 1984.

FINNISH THERMOWOOD ASSOCIATION. Thermowood Handbook. Helsink, 2003. 66 p.

KOLLMANN, F. F. P.; CÔTÉ JUNIOR, W. A. Principles of wood science and technology. Berlin: Springer-Verlag, 1968. 592 p.

PEREIRA, J. C. D. et al. Características da madeira de algumas espécies de eucalipto plantadas no Brasil. Colombo: Embrapa Florestas, 2000. 113 p. (Embrapa Florestas. Documentos, 38). PINCELLI, A. L. P. S. M.; BRITO, J. O.; CORRENTE, J. E. Avaliação da termorretificação sobre a colagem na madeira de Eucalyptus saligna e Pinus caribaea var. hondurensis. Scientia Forestalis, Piracicaba, n. 61, p. 122-132, jun. 2002. PINHEIRO, P. C. C., SAMPAIO, R. S., REZENDE, M. E. A. A produção de carvão vegetal: teoria $e$ prática. 2. ed. rev. e ampl. Belo Horizonte, 2008. $120 \mathrm{p}$.

PONCSÁK, S. et al. A. Effect of high temperature treatment on the mechanical properties of birch (Betula papyrifera). Wood Science and Technology, Berlin, n. 40, p. 647-663. 2006.

QUIRINO, W. F. Utilização Energética dos Resíduos Vegetais. Brasília: LPF, 2002. 31 p. ROCHA, M. P. Eucalyptus grandis Hill ex Maiden e Eucalyptus dunnii Maiden como fontes de matéria-prima para serrarias. Curitiba, 2000. 185 f. Tese (Doutorado em Engenharia Florestal) - Universidade Federal do Paraná, Curitiba, 2000.

SHI, J. L.; KOCAEFE, D.; ZHANG, J. Mechanical behaviour of Québec wood species heat-treated using Thermo Wood process. Wood Science and Technology, Berlin, n. 65, p. 255-259, Mar. 2007.

SKAAR, C. Water in Wood. Syracuse: Syracuse University Press, 1972. 218 p.

STAMM, A. J. Wood and Cellulose Science. New York: The Ronald Press Company, 1964. 549 p.

VITAL, B. R., DELLA LUCIA, R. M. Efeito do aquecimento na estabilidade dimensional e na higroscopicidade da madeira. Revista Árvore, Viçosa, n. 6, v. 2, p. 150-161. 1982. 